\title{
Transparent hood attached to a gastroscope: a simple rescue technique for patients with difficult or incomplete colonoscopy
}

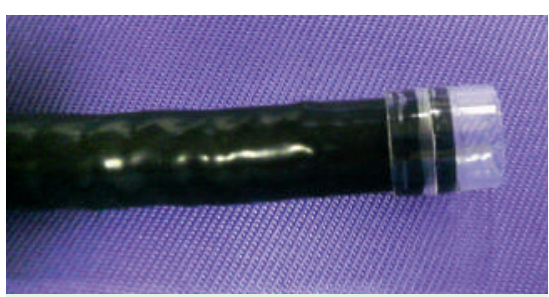

Fig. 1 Example of a transparent hood attached to the tip of the gastroscope. The hood protrudes about $5 \mathrm{~mm}$ in length.

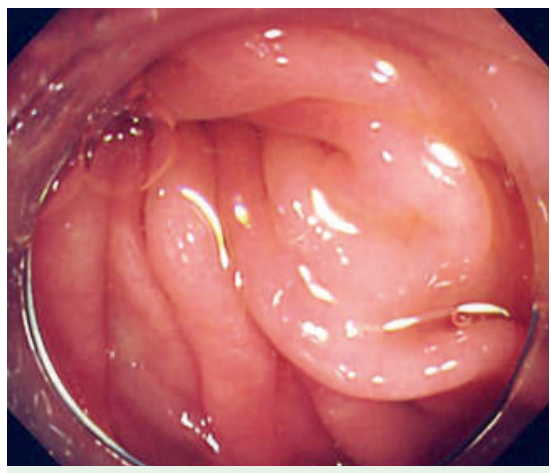

Fig. 2 The transparent hood allows a clear visualization of colonic mucosa with only a little amount of air from the endoscope.

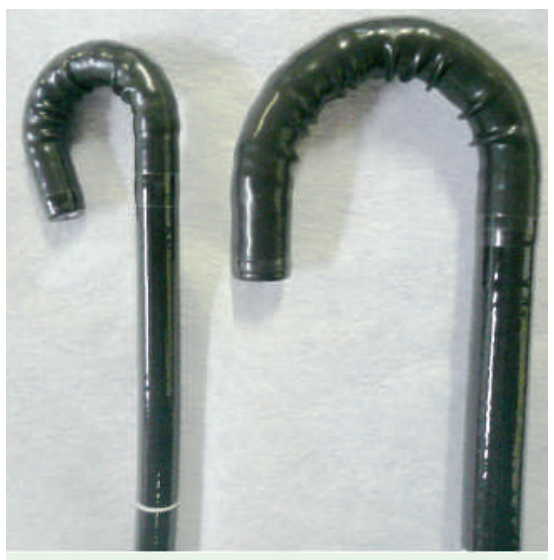

Fig. 3 Comparison between gastroscope (left, GIF-XQ240) and colonoscope (right, CF-Q240I). Note that the caliber of the gastroscope is markedly smaller than the colonoscope.
The use of a transparent hood has recently been reported to be useful in both improving total colonoscopy rates and shortening the cecal intubation time $[1,2]$. We performed a prospective study (From April 2005 to December 2007) to investigate whether a transparent hood attached to a gastroscope improves the cecal intubation rate in difficult colonoscopy cases.

A total of 52 patients who met the criteria of difficult colonoscopy (i.e. not being able to pass the sigmoid colon within 10 minutes, or intolerable pain within 10 minutes of examination) were examined using a gastroscope with a transparent hood attached ( $\bullet$ Fig. 1, 2). Cecal intubation was achieved in 46 patients (88.5\%) by the modified gastroscope. The examination failed in six patients, who were re-examined by removing the transparent hood from the gastroscope, but in none of these patients was further advancement of the scope possible. No complication was seen.

As the use of a gastroscope has been reported to be beneficial in difficult colonoscopy cases $[3,4]$, we supposed that the gastroscope with the transparent hood attached would be effective. The high intubation rate in our study $(88.5 \%)$ may suggest the usefulness of this device. As the caliber of the gastroscope is much smaller than a normal colonoscope, it is much easier to manage the angulated or/ and fixed sigmoid colon ( $\bullet$ Fig. 3). However, a gastroscope requires more torque and rotation of the fiber than a colonoscope because of its limited angulation range (gastroscope: up/down $210^{\circ} / 90^{\circ}$ and right/left $100^{\circ}$, colonoscope: up/ down $180^{\circ}$ and right $/$ left $160^{\circ}$ ). For this reason it may seem better to use a normal colonoscope for the majority of patients in whom insertion is easily performed, and switch to the gastroscope with the transparent hood when difficulty is encountered.
The gastroscope with the transparent hood attached might be a simple alternative method for improving the cecal intubation rate for difficult colonoscopy cases.

Endoscopy_UCTN_Code_TTT_1AQ_2AB

\section{T. Shida', S. Takano', M. Kaiho², M. Miyazaki ${ }^{1}$}

1 Department of General Surgery, Chiba University Graduate School of Medicine, Chiba, Japan

2 Department of Surgery, Kaiho Hospital, Chiba, Japan

\section{References}

1 Lee YT, Hui AJ, Wong VWS et al. Improved colonoscopy success rate with a distally attached mucosectomy cap. Endoscopy 2006; 38: 739-742

2 Kondo S, Yamaji Y, Watabe $H$ et al. A randomized controlled trial evaluating the usefulness of a transparent hood attached to the tip of the colonoscope. Am J Gastroenterol 2007; 102: 75-81

3 Paonessa NJ, Rosen L, Stasik JJ. Using the gastroscope for incomplete colonoscopy. Dis Colon Rectum 2005; 48: 851 - 854

4 Kozarek RA, Botoman VA, Patterson DL. Prospective evaluation of a small caliber upper endoscope for colonoscopy after unsuccessful standard examination. Gastrointest Endosc 1989; 35: 333-335

\section{Bibliography}

DOI $10.1055 / \mathrm{s}-2007-995729$

Endoscopy 2008; 40: E139

(c) Georg Thieme Verlag KG Stuttgart · New York . ISSN 0013-726X

\section{Corresponding author}

\section{T. Shida, MD, PhD}

Department of General Surgery

Chiba University Graduate School of Medicine

1-8-1 Inohana

Chuo-ku

Chiba 260-8670

Japan

Fax: +81-43-2262552

shidax812@yahoo.co.jp 